Acta Poetica 28 (1-2)

PRIMAVERA-OTOÑO

2007

\title{
De la violencia legítima a la violencia revolucionaria
}

\author{
Miriam Jerade Dana
}

En el presente artículo haremos una lectura detallada del ensayo de Walter Benjamin, "Para una crítica de la violencia".

The following paper will attempt to examine Walter Benjamin's essay "Zur Kritik der Gewalt". 

Acta Poetica 28 (1-2)

PRIMAVERA-OTOÑO

2007

Miriam Jerade Dana

Universidad de París

\section{De la violencia legítima a la violencia revolucionaria}

En su ensayo "Para una crítica de la violencia", ${ }^{1}$ Walter Benjamin sostiene que la violencia es el origen y la esencia de la ley. Habría dos tipos de violencia: una que funda la ley, otra que la conserva; la primera legitima al derecho, la segunda resguarda el orden. La particularidad de la tesis benjaminiana es la de subrayar la posibilidad, véase la responsabilidad, de pensar la justicia tanto con relación al derecho, como infinitamente heterogénea a éste. Benjamin presupone una doble tarea de la justicia, por un lado, criticar la violencia que ejerce el derecho y sobre la cual éste funda su autoridad. La segunda, poner en acción una violencia alterna, sin legitimidad ni legitimación, inversa al orden de lo jurídico. Contraria a la concepción de la justicia como "idea" de la cual la ley participa, o fin hacia el que todo sistema político en principio tiende, Benjamin le atribuye a la justicia una tarea dentro de la historia, una dimensión revolucionaria.

La frase que abre el ensayo reza "La tarea (Die Aufgabe) de una crítica de la violencia (Gewalt) puede definirse como

\footnotetext{
${ }^{1}$ El ensayo "Zur Kritik der Gewalt" fue publicado por primera vez en Archiv für Sozialwissenschaft und Sozialpolitik, en agosto de 1921.
} 
la exposición de su relación con el derecho (Recht) y con la justicia (Gerechtigkeit)". ${ }^{2}$ La crítica de la violencia - leyendo crítica en el sentido más amplio, y no únicamente negativo, como examen, juicio, etc. - conlleva una "tarea", que, como veremos, es en todo política. En Benjamin, la reflexión sobre la justicia está ligada a una teoría de la historia, ${ }^{3}$ ya que la crítica de las instituciones que rigen el presente implica un trabajo de genealogía, una memoria revolucionaria que describa el momento de la fundación de aquello que, en su obliteración, justifica la violencia. Intentaremos demostrar, para concluir, que la crítica de la violencia tiene la estructura mesiánica de la promesa: la de hacer advenir, a través de una memoria redentora del pasado, un porvenir inédito.

\section{El derecho, monopolio de la violencia}

Para entender mejor el propósito de Benjamin, me parece importante detenernos un momento en la etimología del término alemán Gewalt. De la raíz latina valere, el término utilizado por Benjamin, que se traduce por "violencia", designa en primer lugar los actos ligados al ejercicio del poder temporal: administrar, reinar, organizar. A este ejercicio están directamente ligadas las nociones de potestas y de vis (fuerza); Gewalt, se podría traducir por fuerza legítima, violencia autorizada, poder legal. Por el hecho de que Gewalt implica el uso de la fuerza, el término se desliza por extensión a la idea de violen-

\footnotetext{
2 Walter Benjamin, "Zur Kritik der Gewalt", en Gesammelte Schriften, Band II.1, Frankfurt am Main, Suhrkamp, 1977, p. 179.

Consulté igualmente la traducción al francés de Maurice de Gandillac, en Oeuvres, I, Paris, Gallimard, 2000. Para la traducción en español consulté la página web $<$ Http://www.philosophia.cl $>$.

${ }^{3}$ Para comprender mejor el concepto de historia en Benjamin, véanse de él mismo Sobre el concepto de la historia y Fragmento teológico político.
} 
cia, es decir, al uso rebelde, revolucionario de la fuerza contra el poder (Macht). Así, Gewalt y Macht comparten la idea de potestas. Gewalt hace una inflexión hacia la vis y la violencia, mientras que Macht tiende más bien a la potentia. ${ }^{4}$

Se habla de violencia en múltiples sentidos, se la adjudica, por ejemplo, a las "fuerzas incontrolables" de la naturaleza. Benjamin hace una restricción y desliga el concepto de violencia de todo aquello que no toque a la moralidad, por ende, a la esfera del derecho y de la justicia, lo que se relaciona con el término Gewalt: aquello que pretende tener autoridad. Tradicionalmente, la filosofía del derecho piensa a la violencia según la relación consecuencial fin y medios. Se postula la violencia como medio en un sistema de fines justos o injustos. Benjamin subraya la diferencia entre el derecho natural y el derecho positivo. El derecho natural considera a la violencia un material bruto, que puede ser utilizado para fines justos o injustos. Así, la violencia estaría justificada según los fines. La teoría del Estado ligada al derecho natural plantea que el individuo, por una decisión racional, hace el sacrificio de su violencia natural en favor del Estado, que vería por una sociedad más justa. Este principio está detrás de toda teoría del "contrato social".

Contemporánea a Benjamin, la concepción de la biología darwiniana, con base en el derecho natural, justifica la violencia como medio original de todos los fines vitales, dicha teoría inspiró la ideología nazi.

En cambio, el derecho positivo no considera a la violencia un elemento natural sino un producto del devenir histórico. Este exige un documento justificativo, ${ }^{5}$ que garantice la justicia por

\footnotetext{
${ }^{4}$ Vocabulaire européen des philosophies. Bajo la dirección de Barbara Cassin, Paris, Le Seuil/Robert, 2004. Entrada "Macht".

5 A partir de esto último podemos pensar la tan conocida frase de una de las siete tesis de Sobre el concepto de la historia, de Benjamin, que habla del documento de cultura como un documento de barbarie.
} 
la legalidad de los medios. Digamos que para el derecho positivo, la violencia es legítima o ilegitima según decisiones históricas. Si el derecho natural justifica los medios por la justicia de los fines, el derecho positivo garantiza la justicia de los medios. Pese a la aparente oposición entre las dos escuelas, éstas coinciden en que: "Si la justicia es el criterio de los fines, la legalidad es el criterio de los medios." (p. 3) El problema de dicha concepción es que no hay un criterio de violencia, sino únicamente de su aplicación. La oposición apenas se desplaza, manteniendo la antinomia entre fines justos y medios justificados. Leemos al respecto : "Porque si el derecho natural es ciego para la incondicionalidad de los fines (Zwecke), el derecho positivo es ciego para el condicionamiento de los medios." (p. 3) Por lo tanto, será necesario encontrar un criterio exterior al derecho.

$\mathrm{El}$ autor propone revisar la situación europea, lo que significa que una crítica de la violencia atiende al presente, a los valores que presupone el poder, a la ideología de las instituciones jurídica y económica, a su presunto origen, a la historia; ${ }^{6}$ sin hacer de ésta el paradigma de lo universal. La máxima general de la legislación europea sostendría que, los fines naturales de los particulares, cuando se persiguen con mayor o menor violencia, entran en conflicto con los fines jurídicos. Frente al singular, el derecho busca monopolizar la violencia. Contrario a quienes suponen que la violencia es lo que está "fuera del derecho" o "fuera de la ley", Benjamin mostrará que ella le es inherente.

La gran sospecha frente al derecho es su interés (Der Interesse des Rechts) por monopolizar la violencia:

Será necesario en cambio tomar en consideración la sorprendente posibilidad que el interés del derecho por monopolizar la violencia respecto a la persona aislada no tenga como explica-

\footnotetext{
${ }^{6}$ Hacia el final del texto Benjamin escribe: "La crítica de la violencia es la filosofía de su historia. La 'filosofía' de esta historia, en la medida en que sólo la idea de su desenlace abre una perspectiva crítica separatoria y terminante sobre sus datos temporales" (p. 17).
} 
ción la intención de salvaguardar fines jurídicos, sino más bien la de salvaguardar al derecho mismo (p. 4).

Así, la prohibición al singular de ejercer violencia no tiene como objetivo proteger fines legales, sino proteger al derecho mismo. Cuando se habla de peligro, o de un individuo peligroso, es porque el derecho se ve amenazado. Benjamin subraya tres realidades que ponen en cuestión al derecho como poder: el delincuente, el derecho a la huelga y la pena de muerte.

\section{La violencia que amenaza al poder}

El análisis benjaminiano de la figura del gran delincuente recuerda, sin hacer ninguna alusión, a la segunda disertación de la Genealogía de la moral de Nietzsche. El criminal (Verbrecherbrechen, romper) viola el contrato social, rompe con el pacto que exige el sacrificio de su violencia, incluso de su singularidad, a cambio de la seguridad y de la comodidad que el estado o la comunidad le proporcionan, y del cual resulta su exclusión. Según Nietzsche, el criminal es un deudor que se burla del prestamista. Sin embargo, Benjamin se refiere aquí también al gran criminal, quien ha provocado la secreta admiración del pueblo, pues, al desafiar el orden jurídico, pone al desnudo la violencia de la ley. El gran criminal ha ganado la admiración de las masas por su oposición al derecho, quizás es quien proclama el Estado de excepción, cuando se suspende la vigencia de la ley, sin que la constitución haya sido disuelta. Un Estado dual, una zona de anomia que pone al descubierto la ficción de la ley. ${ }^{7}$ El soberano tiene un parentesco con el criminal. ${ }^{8}$

\footnotetext{
${ }^{7}$ Véase sobre este punto el libro de Giorgio Agamben, Estado de excepción, Buenos Aires, Adriana Hidalgo, 2003.

8 Algunos autores creen ver en Hitler la figura del gran criminal. Lo que demuestra una anacronía que no es del todo falsa, pues el Estado de excepción que
} 
El derecho a huelga pone en evidencia la violencia que amenaza a la ley y que el derecho concede. Si bien el derecho a huelga se aplica en un primer momento contra el patrón para cambiar algún aspecto de la relación de trabajo o del contrato, siempre acecha la posibilidad de lo que George Sorel llamó la huelga general revolucionaria, es decir, que los trabajadores de todas las empresas hagan valer al mismo tiempo su derecho a huelga. Lo que el Estado califica de abuso, de malentendido por parte de los trabajadores, pues la huelga general destituiría al sistema de derecho, a diferencia de la huelga política que exigiría una modificación en el derecho. Por lo cual, la respuesta del Estado a la huelga general será el uso de la violencia para "resguardar el orden". Es capital entender, en cuanto al análisis que Benjamin hace de la huelga general, que la violencia que puede destruir el orden del derecho está fundamentada en el derecho, como "derecho a huelga": derecho a la violencia, es decir, derecho a destruir el derecho. (Por primera vez en el ensayo, Benjamin utiliza el término destrucción). Dicha contradicción es para Benjamin la esencia misma del derecho. "Para una crítica de la violencia" intenta demostrar que el fundamento de la ley es el acto preformativo que instaura la ley, en otras palabras, el fundamento de la ley es una violencia que transforma las relaciones de derecho, que tiene "fuerza de ley" — para evocar un título de Jacques Derrida— ${ }^{9}$ donde dedica varias páginas al ensayo de Benjamin. Derrida hace énfasis en la expresión en inglés "to enforce the law", que se traduce como "aplicar la ley", y que alude directamente a la

Hitler instaura en Alemania, y que durará doce años, tiene inicio en 1933, mientras que Benjamin escribe su ensayo en 1921. No obstante, todo dictador totalitario, como soberano capaz de proclamar el Estado de excepción, incluye la figura del gran criminal. Me parece capital señalar que la crítica de la violencia no se reduce a los estados totalitarios, sino que analiza sobre todo a las democracias modernas.

9 Jacques Derrida, Fuerza de ley. El fundamento místico de la autoridad, Madrid, Tecnos, 2002. 
idea de una fuerza interior a la ley. El derecho sería entonces una fuerza autorizada.

La misma contradicción que presenta el derecho a huelga presenta el derecho a la guerra que tiene como objetivo fundar un nuevo Estado o una nueva relación de derecho, de ahí que, como Benjamin apunta, ninguna "paz" se concluye sin ceremonial, como reconocimiento de un nuevo "derecho". Sin embargo, en los estados modernos, como explicaremos en seguida, la violencia tiene una función dentro del Estado, incluso del derecho, no para instituir un nuevo derecho sino para conservar el poder, por lo cual el servicio militar es una obligación. "El militarismo es la obligación del empleo universal de la violencia como medio para los fines del estado" (p. 7).

Benjamin distingue entre dos tipos de violencia, una que funda el derecho, otra que lo conserva. El momento de la fundación que interrumpe el antiguo derecho es una zona de anomia; en palabras de Jacques Derrida, la fundación de derecho queda suspendida en el vacío de un acto de lenguaje performativo puro. Para intentar pensar la teoría benjaminiana en términos de la teoría de speach acts, el preformativo ${ }^{10}$ es puro, puesto que por inaugurar un nuevo derecho, no puede ser interpretado según convenciones. Por ello que Derrida llama a estos momentos terroríficos, no sólo por las atrocidades y las violaciones que hay en toda guerra, sino porque la violencia que funda un nuevo derecho no es interpretable. El discurso de su auto-legitimación le es posterior. ${ }^{11}$

La crítica a la pena de muerte no se refiere a una determinada pena o ley, sino que apunta al origen del derecho y sobre

\footnotetext{
${ }^{10}$ Se denomina performativo en la teoría de los actos de lenguaje, aquel acto que se ejecuta por la enunciación. Por ejemplo, "Acepto", es el acto de contraer matrimonio. No obstante, "Acepto" es una convención que está sujeta a ciertas reglas sociales. La promesa, en cambio, es uno de estos actos que produce un paso al límite, puesto que existe únicamente por su enunciación y, si estuviese regida por convenciones, nada la diferenciaría del contrato.

${ }^{11}$ Véase a este respecto Jacques Derrida, Fuerza de ley.
} 
todo, al lazo entre soberanía y Estado de excepción, a la política como decisión sobre la vida y la muerte del ciudadano, a modo de destino. Benjamin apunta: "Pues en el ejercicio del poder de vida y muerte, el derecho se confirma más que en cualquier otro acto jurídico" (p. 8). Uno podría argumentar en contra de la suspensión de la pena de muerte en la mayoría de los Estados democráticos, y fundarla en el imperativo categórico kantiano: "obra en forma de tratar a la humanidad, ya sea en tu persona o en la persona de cualquier otro, siempre como fin y nunca sólo como medio". Esta sería la tesis central del derecho positivo. Benjamin califica de vacía a la crítica moral de la violencia en nombre de la libertad, pues no va al fondo de la cuestión del derecho. Más adelante escribe "Toda violencia como medio, incluso en el caso más favorable, se halla sometida a la problematicidad del derecho en general" (p. 9).

La soberanía se funda, siguiendo el análisis de Giorgio Agamben, ${ }^{12}$ en la exposición de la vida desnuda a la disposición del soberano para dar la muerte. Siguiendo la descripción de Carl Schmitt que Benjamin citará unos años más tarde en su ensayo sobre El drama barroco alemán, el soberano puede proclamar el estado de excepción, está en su poder legal suspender la vigencia de la ley. El soberano es la excepción ya que, simultáneamente, es exterior e interior al orden jurídico. El significado de la pena de muerte no es únicamente castigar una violación al derecho, sino el de darle un estatuto, el de confirmar al poder supremo. Esto se puede leer desde el concepto de bio-política de Foucault, que estudia la relación entre vida desnuda, y soberanía en la época moderna, en donde la subordinación de la vida natural, el simple cuerpo viviente, se integra a los mecanismos y a las estrategias del poder del

\footnotetext{
12 Algunos títulos de Giorgio Agamben, que profundizan en el texto de Benjamin, y que nos permitimos sugerir al lector, son: Estado de excepción; Homo Sacer. El poder soberano y la vida desnuda; y el ensayo "Le Messie et le souverain”, recogido en La Puissance de la pensée, Paris, Payot et Rivages, 2006.
} 
Estado. Podríamos arriesgar lo siguiente: pese a la abolición de la pena de muerte, su principio se "conserva virtualmente", incluso de manera aún más violenta, en las democracias modernas, en una zona de indistinción, por ejemplo, entre vida privada y vida pública (según un concepto de Hannah Arendt), o entre poder ejecutivo y poder legislativo. En la policía, Benjamin verá la zona de indistinción entre violencia fundadora y violencia conservadora, entre violencia y derecho.

\section{La zona de anomia}

Si hasta ahora nos vimos confrontados al problema de la violencia fundadora de la ley, la crítica de la violencia conservadora presenta una mayor complejidad. Benjamin percibe en la policía moderna la zona de indistinción entre las dos violencias, ahí donde la violencia, para conservar, ordena. La violencia de la policía, que es utilizada para fines legales, crea en todo momento la ley sin que ese momento pueda ser localizado, inscrito o escrito, de ahí la dificultad para criticarla. La fundación de un nuevo derecho implicaba una decisión, una "categoría metafísica". En cambio, la violencia de la policía conserva suspendiendo, sus actos tienen fuerza de ley y, con el pretexto de "salvaguardar la ley", toma decisiones que están fuera de la ley, no para crear otro orden de derecho, pues su fin es la conservación del poder. Benjamin escribe: "La policía es un poder con fines jurídicos (con poder para disponer), pero también con la posibilidad de establecer para sí misma, dentro de vastos límites, tales fines (poder para ordenar)" (p. 8).

En inglés se denomina expresamente "la fuerza", the "for$c e ”,{ }^{13}$ la policía es la fuerza de ley sin ley. En los Estados mo-

\footnotetext{
${ }^{13}$ En español, la expresión no menos alegórica: fuerzas armadas hace referencia al ejército. Actualmente, en la mayoría de los Estados-Nación, el ejército ejecuta las tareas propias a la policía. Una causa de esto son las nuevas tecnologías de guerra. En la era actual el conflicto económico predomina sobre el conflicto armado.
} 
dernos la policía juega un papel preponderante, sobre todo por su visibilidad. El arma no tiene como fin la disuasión, ella es el símbolo de lo que amenaza porque se siente amenazado, es decir: el derecho. Auto-inmunidad que mientras más defiende, más se expone. La policía, como veremos, devela la fragilidad del sistema, de la soberanía. A este respecto leemos en "Para una crítica de la violencia":

Incluso "el derecho" de la policía marca justamente el punto en que el estado, sea por impotencia, sea por las conexiones inmanentes de todo ordenamiento jurídico, no se halla ya en grado de garantizarse - mediante el ordenamiento jurídicolos fines empíricos que pretende alcanzar a toda costa. Por ello la policía interviene "por razones de seguridad" en casos innumerables en los que no subsiste una clara situación jurídica cuando no acompaña al ciudadano, como una vejación brutal, sin relación alguna con fines jurídicos, a lo largo de una vida regulada por ordenanzas, o directamente no lo vigila (p. 9).

Espectral, acompaña la vida del ciudadano, lo vigila. Benjamin califica la violencia policíaca de amorfa y a su manifestación de fantomática. Es ubicua y a la vez ilocalizable, interviene cuando "la situación jurídica no es clara", es decir, su fuerza está en interpretar la ley según las necesidades del poder. La policía crea una indecisión entre la promulgación de derecho y su aplicación. Es justamente en las democracias modernas donde la violencia de la policía degenera, en razón de la separación de poderes. Si en la monarquía absoluta el poder ejecutivo y el poder legislativo están unidos en la figura del soberano, en las democracias modernas -industriales, globales, tecno-liberales - los poderes se confunden y la policía termina por ser el cuerpo espectral del poder. ${ }^{14}$

14 Giorgio Agamben señala en su libro Medios sin fin (Valencia, Pre-textos, 2001) la investidura del soberano como agente de policía, en los estados totalitarios. Esto implica hacer del adversario un criminal excluido de la comunidad o de la 


\section{Medios sin fin}

Benjamin nos previene. No hay una eliminación de conflictos completamente exenta de violencia, y ésta no puede, en ningún caso, resolverse mediante un contrato. Esto contradice las teorías que sostienen que una sociedad democrática más justa ${ }^{15}$ es aquella donde se crean contratos de común acuerdo. Por una parte, el contrato otorga derecho a recurrir a la violencia si uno de los contratantes lo incumple; por otra, la institución que garantiza el cumplimiento del contrato se funda en la violencia o se ha instalado en el poder gracias a una violencia fundadora de derecho y, por decirlo así, el contrato redobla esta primera violencia, pues su autoridad es por su capacidad de iteración, gracias a la obliteración de ese momento fundador.

Benjamin se pregunta si existe alguna esfera de la vida humana exenta de violencia. "Hay una esfera hasta tal punto no violenta de entendimiento humano que es por completo inaccesible a la violencia: la verdadera y propia esfera del 'entenderse', la lengua" (p. 10).

Justamente, el lenguaje, no aquél que sería medio o comunicación — puesto que hemos visto hasta ahora que todo medio conlleva violencia-, sino aquél que es "medio puro", es decir, aquello que, según la tradición de la cultura del corazón, sin fundar un contrapoder, hace un orden alterno al poder $y$ exento de violencia, como el amor, la confianza, la simpatía; siempre y cuando estos se den como soluciones mediatas en el ámbito de las relaciones privadas, concretas, entre hombres y bienes. Es por ello que la técnica, dice Benjamin, es su dominio más propio. Por ejemplo, el diálogo considerado como

vida civil. Es notorio que la solución final se halla realizada a través de un cuerpo de policías y que no exista ningún documento que la avale, aparte de la conferencia de Wannsee el 20 de enero de 1942, entre un grupo de funcionarios de policía, según testimonio de Adolf Eichmann.

15 Benjamin critica tanto el parlamentarismo como las democracias liberales. 
técnica de acuerdo civil. Esto último nos podría hacer creer que el diálogo racional entre ciudadanos es la respuesta a la violencia, lo sorprendente es que Benjamin encuentra como prueba de este terreno de acuerdo entre los hombres, la impunidad de la mentira.

Autores contemporáneos a Benjamin y a los totalitarismos del siglo xx como Arendt ${ }^{16}$ o Koyrè ${ }^{17}$ han hecho hincapié en el papel que juega la mentira en los Estados totalitarios, donde hay una vigilancia excesiva al discurso externo a la propaganda. Si bien el totalitarismo funda su poder en un mito, la mentira es castigada, generalmente con la tortura, con el fin de mostrar el lugar del poder en el cuerpo a través del dolor, imposibilitando toda respuesta discursiva. ${ }^{18}$ Contraria a la impresión de fortaleza que da todo Estado represivo, el terror es la pérdida de confianza en su propia violencia. Benjamin muestra que toda violencia conservadora, a la larga, debilita indirectamente la violencia fundadora, es decir, el derecho que ésta representa.

Otro ejemplo de "medio puro" es la huelga general proletaria de la que habla George Sorel, que busca la supresión total del Estado, prohibiendo todo programa, toda fundación jurídica. Por ser medio puro, la huelga general es no violenta (gewaltlos). En la diplomacia, Benjamin encuentra igualmente un modo de acuerdo no violento, externo al derecho.

Se trata de buscar otro tipo de violencia, y ésta rompería con el dogma fundamental de la teoría jurídica pero también con la cuestión de la verdad, dice Benjamin, de menos, de la verdad resultante de una cierta lógica. "Fines justos pueden ser

\footnotetext{
${ }^{16}$ Hannah Arendt, "Truth and politics", en Between Past and Future: Eight Exercises in Political Thought, New York, The Viking Press, 1968.

${ }^{17}$ Alexandre Koyrè, Reflexiones sobre la mentira, trad. Hugo Sabino, México, Siglo XXI.

${ }^{18}$ Sobre la tortura y el lenguaje nos permitimos recomendar al lector el brillante trabajo de Elaine Scarry. Cf. The body in pain, The making and Unmaking of the World, Oxford, Oxford University Press, 1985.
} 
alcanzados por medios legítimos, medios legítimos pueden ser empleados para fines justos" (p. 13). Benjamin habla de una "violencia pura" dentro de la acción humana, una que ni funda ni conserva el derecho, y que, a su vez sería "medio puro" en contradicción con los fines:

Y si toda especie de violencia destinada, en cuanto emplea medios legítimos, resultase por sí misma en contradicción inconciliable con fines justos, pero al mismo tiempo se pudiese distinguir una violencia de otra índole, que sin duda no podría ser el medio legítimo o ilegítimo para tales fines y que sin embargo no se hallase en general con éstos en relación de medio, ¿en qué otra relación se hallaría? (p. 13)

En "Sobre el lenguaje en general y sobre el lenguaje humano", ${ }^{19}$ Benjamin postula un lenguaje que no es medio de comunicación, sino pura manifestación de la esencia espiritual. Con la caída del paraíso, el hombre habría abandonado el lenguaje puro, que se asemeja al acto divino de nombrar, por el juicio. Recobrarlo no implicaría construir otra lengua, sino que éste se manifestaría en la gramática de las lenguas comunicantes. No es casualidad si, al momento de plantear la problemática de la justicia en términos metafísicos, Benjamin alude a una imposibilidad de decisión en la lengua, lo que nos hace pensar que hay una relación entre justicia y lenguaje. Si bien toda lengua tiene sus "reglas", hay siempre una zona de anomia, la posibilidad de estar fuera de la ley y, en un acto no menos violento, firmar la lengua a partir de la singularidad, ${ }^{20}$ es decir, prometer la lengua a una escucha que estaría siempre

${ }^{19}$ Redactado en el mes de noviembre de 1916, a manera de carta dirigida a Gershom Scholem.

${ }^{20}$ En el ensayo de Benjamin sobre Karl Kraus leemos: "Venerar la imagen de la justicia divina considerara como lengua —en el corazón mismo de la lengua alemana - tal es el peligroso salto auténticamente judío por medio del cual (Kraus) intenta escapar a la empresa del demonio". 
por-venir. En el siguiente párrafo, converge una experiencia de la insolubilidad de los problemas jurídicos con una imposibilidad de decidir lo justo en las lenguas en desarrollo:

Se iluminaría así la singular y en principio desalentadora experiencia de la final insolubilidad de todos los problemas jurídicos (que, quizás en su falta de perspectivas, puede compararse sólo con la imposibilidad de una clara decisión respecto a lo que es "justo" o "falso" en las lenguas en desarrollo.) Porque lo cierto es que respecto a la legitimidad de los medios y a la justicia de los fines no decide jamás la razón, sino la violencia destinada sobre la primera y Dios sobre la segunda (p. 13).

En lo siguiente intentaremos analizar quizás la parte más críptica del ensayo, pues nos alejaremos del orden de la "razón" para entrar en el del "destino" o lo que Benjamin entiende por violencia mítica y violencia divina. Decir lo justo es una experiencia de lo imposible, un paso al límite, la insolubilidad que es más bien una "indecibilidad" (Unentscheidbarkeit), incapacidad de decidir según una regla universal, según una lógica, o un concepto racional de libertad. ¿Acaso la exigencia de otra lengua? ¿La de una experiencia de la justicia única, y a su vez, susceptible de universalización? ¿Puede la "indecibilidad" actuar políticamente? Espero dar al lector algunas luces sobre el texto de Benjamin, que en esta última parte nos enfrenta a un límite de la interpretación. Ahí donde el saber, la lógica y toda teoría del significado se anulan, abriendo paso a la creencia, a una especie de intuición que concentra la memoria de una violencia originaria y su redención, en una ruptura de la continuidad histórica, instante que promete el por-venir, a partir de la crítica de la experiencia política del presente. 


\section{Violencia mítica y violencia divina}

En la octava tesis de Sobre el concepto de historia, Benjamin escribe:

La tradición de los oprimidos nos enseña que el "estado de excepción" (Ausnahmezustand) en que vivimos es la regla. El concepto de historia al que lleguemos debe resultar coherente con ello. Promover el verdadero estado de excepción se nos presentará entonces como tarea nuestra, lo que mejorará nuestra posición en la lucha contra el fascismo. La oportunidad que éste tiene está, en parte no insignificante, en que sus adversarios lo enfrenten en nombre del progreso como norma histórica. - El asombro ante el hecho de que las cosas que vivimos sean "aún" posibles en el siglo veinte no tiene nada de filosófico. No está al comienzo de ningún conocimiento, a no ser el de que la idea de la historia de la cual proviene ya no puede sostenerse.

El término Ausnahmezustand es, en cierto modo, una cita implícita de la misma noción según Carl Schmitt, quien puso en relieve la paradoja del estado de excepción. Está en la capacidad del soberano suspender la ley en ocasiones extraordinarias. La paradoja radica en que la suspensión de la ley está avalada por la ley; por lo cual, el estado de excepción es más bien la regla. Esto ha implicado un estado que, pese a que dice valer la "igualdad", ha justificado, con el pre-texto - y el texto- de una tradición, la opresión. La pregunta se impone: ¿cuál es la concepción de la historia que, según Benjamin, logrará hacer un estado de excepción efectivo, es decir, uno en donde la puesta entre paréntesis de la ley no instaure un orden de poder sino uno de justicia? Intentaremos mostrar por qué dicha concepción del tiempo en Benjamin es mesiánica. Ahí donde lo político toca lo religioso, en el sentido que lo religioso, en tanto mesianismo, revela el problema de la justicia. 
Tradicionalmente, se piensa que la posibilidad del derecho radica en la universalización de los fines. Benjamin se pregunta por la posibilidad de una "mediación" pura, sin vistas a un fin. En la experiencia cotidiana de la cólera encuentra un ejemplo de una violencia in-mediata, manifestación sin mediación. La violencia mítica resulta de la cólera de los dioses. El autor alude aquí a la fatalidad que cae sobre Niobe, por la cólera de Artemisa y Apolo, que no es un castigo por haber violado la ley, sino un desafío al destino y, por la victoria de este último, la instauración de un nuevo orden de derecho. Benjamin califica a esta violencia de ambigua, pues la sangrienta muerte de los hijos de Niobe ${ }^{21}$ no es propiamente destructiva, respeta la vida de la madre. El héroe lucha contra el destino, con la esperanza de aportar a los hombres un nuevo orden de derecho, esto último está detrás de la figura del gran delincuente (que ahora Benjamin denomina großen Missetäter, término que designa un actor, que debería ser traducido por "el gran malhechor". Es importante subrayar que la violencia revolucionaria radica en el ámbito de la acción humana). Si bien la violencia mítica parece análoga a la violencia fundadora de derecho, la primera no tiene carácter de medio sino de destino. El término destino vuelve una y otra vez en el texto, y es quizás lo que lo hace tan oscuro. El destino es ineluctable, impide pensar la historia en términos de causa-efecto. La violencia mítica, al igual que el destino, ejecuta. En cambio, la violencia divina manifiesta.

A diferencia de la violencia mítica, la violencia divina no es fundadora de derecho: "Creación de derecho es creación de poder, y en tal medida un acto de inmediata manifestación de violencia. Justicia es el principio de toda finalidad divina, poder, el principio de todo derecho mítico" (p. 15).

${ }^{21}$ Mujer del rey de Tebas, concibió siete hijas y siete hijos. Se vanagloria de su fertilidad frente a Leta, quien sólo tiene dos hijos: Artemisa y Apolo. Estos últimos matan en venganza a los hijos de Niobe, quien permanece con vida cargando una gran culpabilidad. 
La creación de un Estado, producto de la "paz" como definición de fronteras, es el "fenómeno originario" de toda violencia fundadora de derecho. Ley y poder tienen una génesis simultánea, como apropiación de un territorio. Encontramos en este párrafo una cita de Sorel, quien escribió que todo derecho (Recht) fue en un primer momento privilegio. (Vor-recht, el guión sugiere un "pre"-derecho. ${ }^{22}$ Lo que nos hace pensar en la compleja relación entre propiedad y responsabilidad.). Sin embargo, la ley reconoce al adversario como "igual", lo que Benjamin califica de "demoníacamente ambiguo". Esta "equidad desigual", esta ambigüedad de privilegios que se encubren en la "igualdad" ("violencia discrecionaria" es otro nombre que el autor le da a la violencia fundadora), nos hace pensar en el engranaje de la maquinaria económica. Irrumpe en el texto, con risa irónica, una cita de Anatole France: "Prohíben por igual a ricos y a pobres pernoctar bajo los puentes". Quien osa transgredir las fronteras, que en un principio fueron definidas por una ley no escrita, está sometido a la expiación. Por lo tanto, podemos decir que la justicia no conoce de equidad. A la violencia mítica se opone la violencia divina: "Si la violencia mítica funda el derecho, la divina lo destruye; si aquélla establece límites y confines, ésta destruye sin límites, si la violencia mítica culpa y castiga, la divina exculpa; si aquella es tonante, ésta es fulmínea; si aquélla es sangrienta, ésta es letal sin derramar sangre" (p. 16).

Al mito de Niobé el autor contrapone el juicio de Dios contra la banda de levitas de Korah, a quienes sin previa amenaza aniquila sin derramar sangre. En la sangre se juega la oposición entre las dos violencias; ellas representarían, para Benjamin, la diferencia entre la concepción griega y la hebrea, entre la onto-teo-logía y lo mesiánico. "La violencia mítica es violencia sangrienta sobre la desnuda vida en nombre de la violencia, la pura violencia divina es violencia sobre toda vida en

22 Nota de Maurice de Gandillac a la edición francesa. 
nombre del viviente. La primera exige sacrificios, la segunda los acepta" (p. 16).

El poder protege la vida desnuda, porque puede en cualquier momento darle muerte. En cambio lo religioso considera a la vida sagrada. La violencia divina acepta el sacrificio, sin por eso dejar de ser violenta; su fin no es la fundación de poder, prefiere, no a la vida, sino al viviente: la vida sagrada no es la pura existencia sino la existencia justa. Es por eso que el principio "No matarás", no resulta de una "decisión libre" o del "imperativo categórico", sino de una exterioridad de la ley al presente de la voluntad. Responsabilidad infinita, sin límites, Benjamin pone al judaísmo como ejemplo, que se opone al asesinato por legítima defensa, límite del derecho, ahí donde lo inmoral es, según el caso, legítimo. El hombre no es justo en el sentido de una esencia o cualidad, mucho menos en el sentido de una inocencia original; lo sagrado de la vida es la existencia justa que no está actualizada, sino prometida en un "aún no": "el no-ser del hombre es algo más terrible que el (además: sólo) no-ser-aún del hombre justo” (p. 17). ${ }^{23}$

Lo mesiánico, más que una creencia en el Mesías, es una creencia en el advenimiento de un tiempo otro, ${ }^{24}$ si la violencia mítica es una ruptura dentro de la historia, el tiempo mesiánico es una ruptura con el tiempo histórico y por lo tanto, no es cognoscible. Por eso Benjamin escribe que sólo se puede conocer con certeza la violencia mítica. ${ }^{25}$

\footnotetext{
${ }^{23}$ Encontramos ecos de esta problemática de Benjamin en la ética de Levinas, donde el rostro del otro exige el no matarás y en Derrida, en Fuerza de ley, la siguiente paradoja: La deconstrucción es la justicia. La justicia es indeconstructible. Lo que podríamos interpretar así: la deconstrucción como crítica de la violencia es la justicia, pero la justicia es indeconstructible, porque si no sería ley. Conceptos como pasividad, hospitalidad, indecidabilidad, aporía, santidad, etc. pueden ser leídos como una respuesta a la problemática en Benjamin del derecho. Esto ha llevado, por ejemplo, a Derrida, a plantear una política de la hospitalidad como memoria de la violencia, y crítica de la ley que hace a las fronteras.

${ }^{24}$ Compárese con el inicio del "Fragmento teológico-político".

${ }^{25}$ Lo que no sería un simple saber, sino un deber, el deber de la crítica de la violencia deja entrever la justicia.
} 
El tiempo mesiánico sería una suspensión del derecho y del Estado, es decir, de la fuerza que hace la ley, quizás de una ley que sigue vigente sin significar y que se abre a la posibilidad de una fuerza sin violencia: "Sobre la interrupción de este ciclo que se desarrolla en el ámbito de las formas míticas del derecho sobre la destitución del derecho junto con las fuerzas en las cuales se apoya, al igual que ellas en él, es decir, en definitiva del estado, se basa una nueva época histórica" (p. 18).

Tiempo que no sería continuación, sino redención del pasado por la memoria de la opresión. Violencia revolucionaria, cuya efectividad, al no estar determinada por la historia, no radica en la administración ni en la fundación de poder sino en "lavar la falta", lo que nos lleva al terreno de la ética. ¿Cómo pensar, a partir de lo mesiánico, la política, más allá de las instituciones, de la administración, de la protección de fronteras, de la economía con base en la guerra, de la policía? Benjamin parece sugerirnos la posibilidad —incalculable — de una política que se funda en la ética y de una ética por encima de toda decisión, de toda Ley. El tiempo mesiánico de justicia podría en cualquier momento entrar por la puerta entreabierta del ahora.

Misteriosa irrumpe la última frase del texto, que se graba en la cadencia de la enunciación cual destino: "La violencia divina, que es insignia y sello, nunca instrumento de sacra ejecución, puede ser nombrada soberana" (p. 18). ${ }^{26}$

\footnotetext{
26 Traducción libre. La versión española dice "[...] es la violencia que gobierna", pero preferí cambiar por "soberana", lo que hace eco a la cuestión de la soberanía como Estado de excepción. En alemán dice "die waltende heiBen". Derrida ha jugado con la resonancia entre waltende y Walter, el nombre de pila del autor, lo que nos llevaría a una reflexión sobre el singular y la ley que, como en Frente a la Ley de Franz Kafka, es el único que puede entrar por la puerta de la ley, ya de por sí entreabierta.
} 


\section{BIBLIOGRAFÍA}

Agamben, Giorgio, Medios sin fin, Valencia, Pre-textos, 2001.

- Estado de excepción, Buenos Aires, Adriana Hidalgo, 2003.

- La Puissance de la pensée, Paris, Payot et Rivages, 2006.

- Homo sacer. El poder soberano y la nuda vida, Valencia, PreTextos, 2003.

- Medios sin fin, Valencia, Pre-textos, 2001.

Arendt, Hannah, "Truth and politics", en Between Past and Future: Eight Exercises in Political Thought, New York, The Viking Press, 1968.

Benjamin, Walter, Gesammelte Schriften, Frankfurt am Main, Suhrkamp, 1977.

— "Karl Kraus", en Obras, libro II, vol. 1, trad. Jorge Navarro Pérez, Madrid, Abada, 2007.

Derrida, Jacques, Fuerza de ley. El fundamento místico de la autoridad. Madrid, Tecnos, 2002.

Koyrè, Alexandre, Reflexiones sobre la mentira, trad. Hugo Sabino, México, Siglo XXI.

SCARRY, Elaine, The body in pain. The making and Unmaking of the World, Oxford, Oxford University Press, 1985. 